\title{
New Aminocoumain as Corrosion Inhibitor
}

\author{
Yasameen K. Al-Majedy \\ Department of Applied Science, Branch of Chemistry, University of Technology (UOT), \\ Baghdad-Iraq. \\ Corresponding author: yasmin.chem79@gmail.com.
}

\begin{abstract}
New green organic molecules as corrosion inhibitor namely, 2-amino-4-(4-nitrophenyl)-3cyano-4, 5-dihydropyrano (3,2-c) coumarin (AND) was synthesized starting from 4hydroxycoumarin, malonitraile and 4-nitrobenzaldehyde and tested on mild steel (MS) in $1 \mathrm{M} \mathrm{HCl}$ media by a weight loss method and identification of the surface technique employee scanning/electron/microscope (SEM) studies. The AND as an inhibitor compound have been elucidate spectroscopically (FT-IR , ${ }_{1}^{1} \mathrm{HNMR}$ and ${ }^{13} \mathrm{CNMR}$ ) The weight loss investigation demonstrated that inhibition performances have been improved via concentration raising of inhibitor. To support our results scanning electron microscopy was employed to clarify the surface of the MS with and without AND in $1.0 \mathrm{M} \mathrm{HCl}$ media. The inhibition performance rate was $96 \%$ at the maximum utilized concentration of AND. [DOI: 10.22401/JNUS.21.2.08]
\end{abstract}

Keywords: 4-hydroxycoumarin; 4-nitrobenzaldehyde; malonitraile; SEM.

\section{Introduction}

Mild steel has been utilized as some auxiliary materials for reactors of vessels, tanks, and pipeline, so forth that were known to consume perpetually in contact with different solutions. From the view purpose of country's economy and monetary ramifications of consumption peril, it is important to embrace fitting means and approaches to decrease the misfortunes because of erosion. In acidic/basic fluid conditions, its corrosion and counteractive action are all around considered, however in non-aqueous solvents restricted reports are accessible [1-4]. The inhibitory activity practiced by organic compounds on disintegration of materials species are typically identified with adsorption cooperation among inhibitors and surface of MS [5-7]. The planarity (p) and lone pairs of electrons present on $\mathrm{N}$, and $\mathrm{O}$ atoms are important structural features that control the adsorption of these molecules onto the surface of the metal. The reason for this work was to confirm the already settled outcomes on the consumption restraint impact of heterocyclic compound on mild steel in acidic media [8-9]. Numerous specialists have revealed that the restraint impact depends for the most part on many physic/chemical with electronic characteristics of the natural inhibitors identified with functional groups, steric/ impacts, electronic thickness of contributor iotas and orbital significant for electrons giver [10-12]. We focused on the synthesis of new heterocyclic compound as novel natural consumption inhibitor. We report the amalgamation of AND, and concoction structure illustration utilizing spectroscopic strategies (i.e., IR and NMR). Late investigations have demonstrated that natural compound containing polar functional groups are very productive in limiting the impact of erosion not withstanding heterocyclic compound having polar gatherings and $\pi$ electrons. The atomic outline of the AND particle is comprises of $\mathrm{NH}_{2}, \mathrm{NO}_{2}$, keto and $\pi$ electrons, which could successfully contributes toward reducing of $\mathrm{MS}$ consumption in $\mathrm{HCl}$ solution. Suggested structure for combined consumption inhibitor is appeared in Fig.(1). 


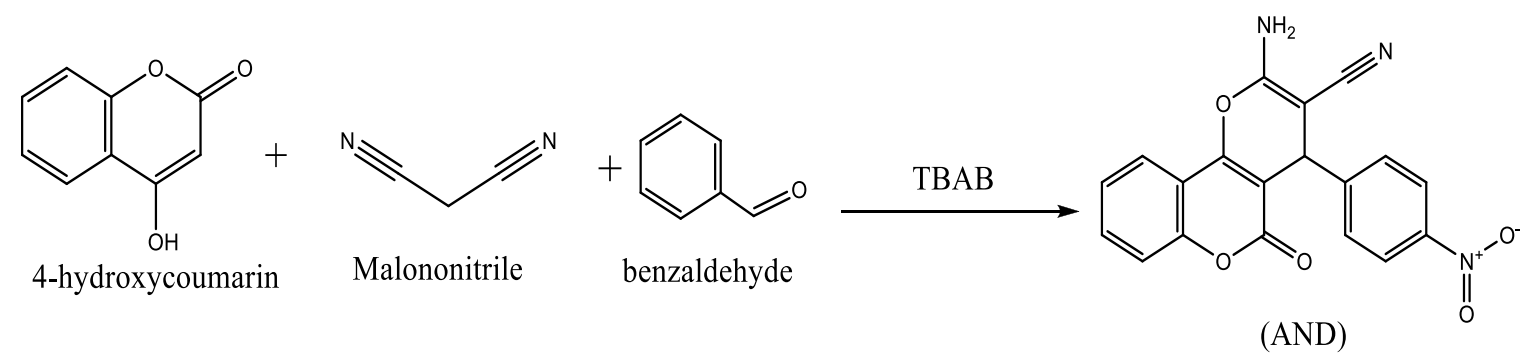

Fig.(1): Structure that suggested of the prepared corrosion inhibitor AND.

\section{Experimental}

\subsection{Synthesis and elucidation of AND}

The inhibitor AND has been prepared through the reaction of benzaldehyde (2.5 mmol), malononitrile (3.75 mmol), and 10 $\mathrm{mL}$ of water. The reaction mixture has been stirred. TBAB (tetrabutyl ammonium bromide $10 \mathrm{~mol} \%$ ) have been adding to reaction media stirring and 4-hydroxycoumarin $(2.5 \mathrm{mmol})$ was added. For 3 hrs. the solution has been reflux and the disappearance of reactants was figured according to TLC technique. the mixture left to cool at $25^{\circ} \mathrm{C}$ then filtered and crystallized with ethanolic alcohol (hot) to get the target compound [13], yield 75\%, M.P $\left(212-214^{\circ} \mathrm{C}\right)$.

\subsection{Gravimetric Approaches}

\subsubsection{MS specimens.}

MS specimens got by the Metal Samples Company were employed all through this investigation. The composition (wt \%) of the mild steel was as follows: $\mathrm{Fe}, 99.21$; C, 0.21; $0.38 ; 0.09 ; 0.05 ; 0.05$; and 0.01 for $\mathrm{Fe}, \mathrm{Si}, \mathrm{P}$, $\mathrm{S}, \mathrm{Mn}, \mathrm{Al}$ respectively. The measurements were conducted in aerated, non-stirred $1.0 \mathrm{M}$ $\mathrm{HCl}$ solutions containing different concentrations of AND compound.

\subsubsection{Technique of Weight Loss}

Copouns in duplicate were suspended in $200 \mathrm{~mL}$ of the examine media, with \& without the AND corrosion Inhibitor of different concentration $\left(0 \times 10^{-2} \mathrm{mM}, 5 \times 10^{-2} \mathrm{mM}\right.$, $10 \times 10^{-2} \mathrm{mM}, 15 \times 10^{-2} \mathrm{mM}, 20 \times 10^{-2} \mathrm{mM}$, $25 \times 10^{-2} \mathrm{mM}$ and $50 \times 10^{-2} \mathrm{mM}$ ), for $1,2,3,4$, $5,10,24,48$ and $72 \mathrm{hrs}$. at room temperature, [14] Specimens weights for before/after immersed was computed. Inhibition efficiency of the mild steel was determined using the average of the duplicate value using the equation:
Inhibition Efficiency $(\mathrm{IE} \%)=\left(1-\mathrm{W}_{2} / \mathrm{W}_{1}\right) \times 100$

Where, $\mathrm{W}_{1}$ and $\mathrm{W}_{2}$ are weight loss of MS without and with the AND.

\section{Results and Discussion}

\subsection{Identification of AND}

The investigated compound of coumarin derivative have been proved regarding to spectroscopically techniques namely FTIR and NMR. According to spectrum of the FTIR the inhibitor demonstrated the bands at $2195.1 \mathrm{~cm}^{-1}$ for $\mathrm{C} \equiv \mathrm{N}$ and $3482.0-3429.8 \mathrm{~cm}^{-1}$ for $\mathrm{NH}_{2}$, $1605-1594.7 \mathrm{~cm}^{-1}$ for N-N str. $1430 \mathrm{~cm}^{-1}$ for C-N str., $1717 \mathrm{~cm}^{-1}$ for $\mathrm{C}=\mathrm{O}$ str. and $1370-1456$ $\mathrm{cm}^{-1}$ for $\mathrm{C}-\mathrm{O}$ str. 


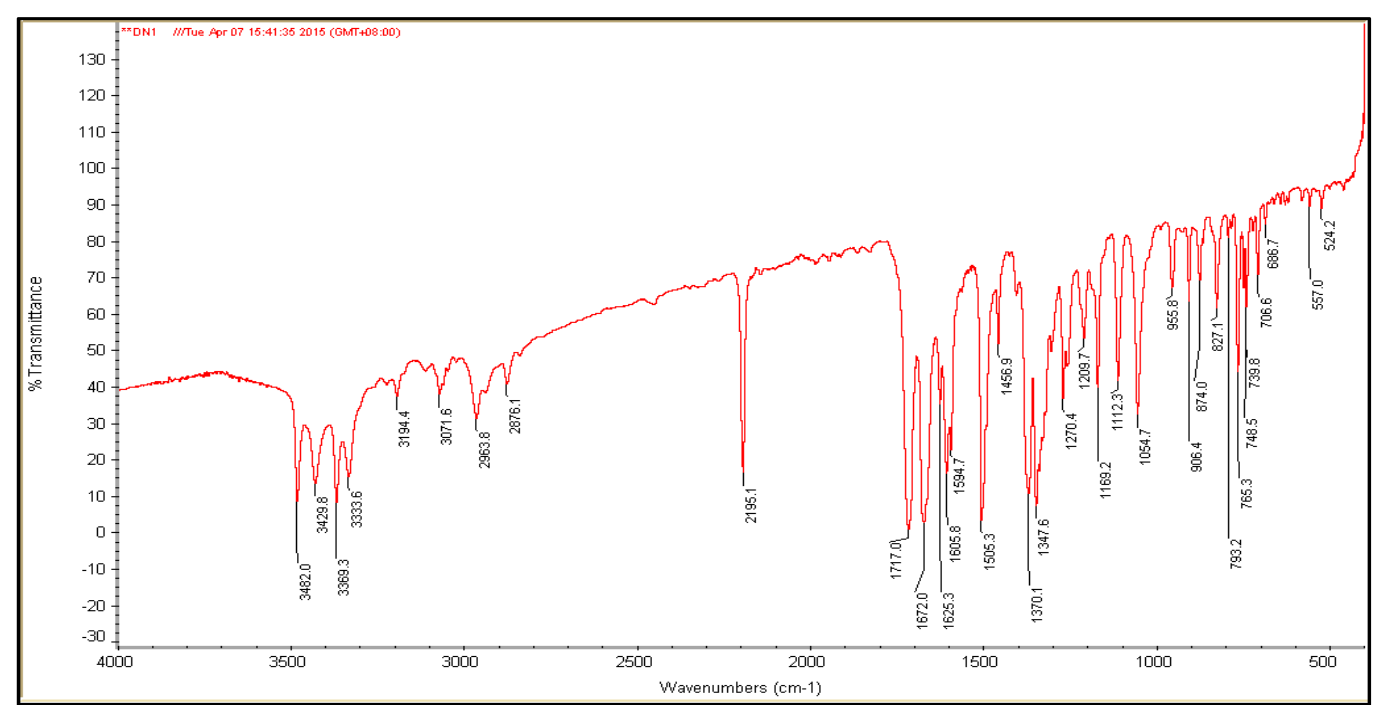

Fig.(2): FTIR spectra of AND.

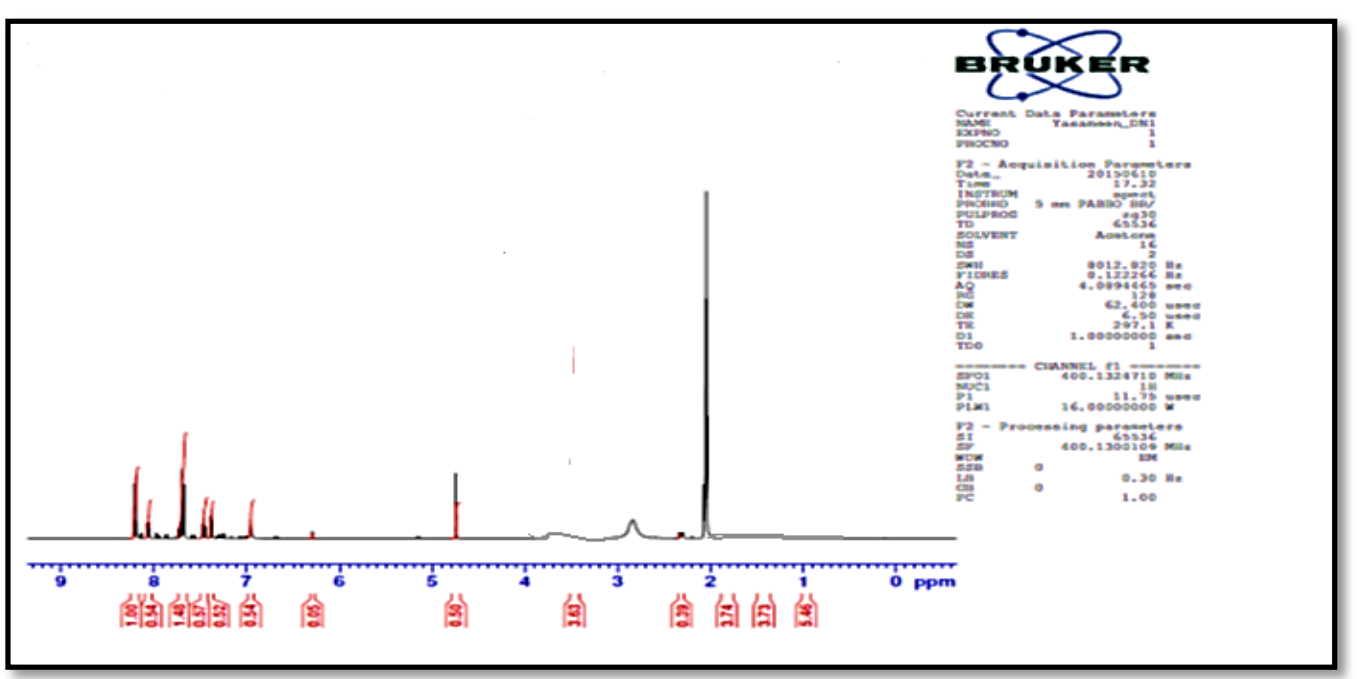

Fig.(3): ${ }^{1}$ HNMR spectrum of AND.

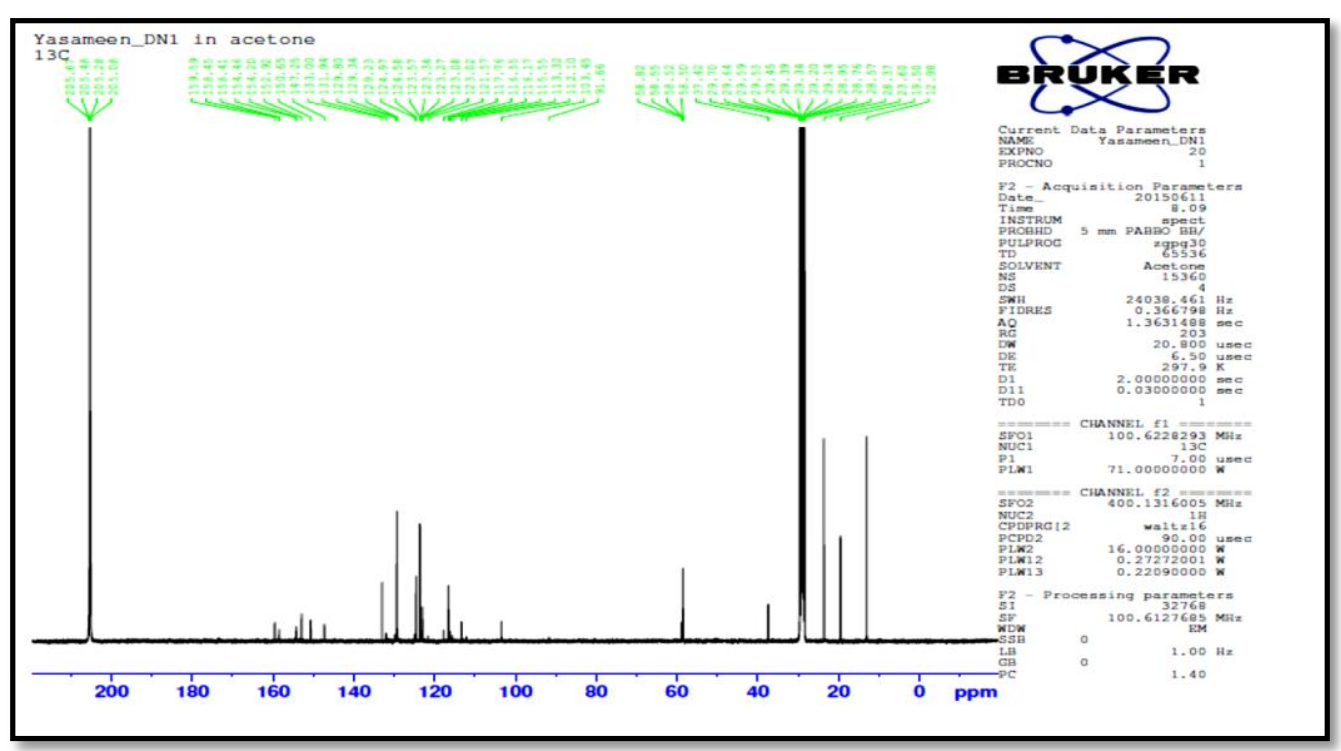

Fig.(4): ${ }^{13}$ CNMR spectrum of AND. 
${ }^{1} \mathrm{H}-\mathrm{NMR}\left(\mathrm{CDCl}_{3}\right)$ : refers to the presence of (s, $\mathrm{NH}_{2}$ group) at $\delta 8.49 \mathrm{ppm}$. The compound showed prominent singlet at $\delta 8.14, \mathrm{~s}, 1 \mathrm{H}$ and $4.25, \mathrm{~s}, 1 \mathrm{H}$ for $(\mathrm{CH})$ groups and $(\delta$ 7.4$7.75), \mathrm{m}, 4 \mathrm{H}$ for aromatic ring, ${ }^{13} \mathrm{C}-\mathrm{NMR}$ $\left(\mathrm{CDCl}_{3}\right)$ : $166.9,162.4,152.3,144.3,125.4$,

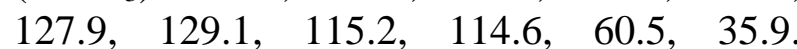
Regarding to FTIR, ${ }^{1} \mathrm{HNMR}$ with ${ }^{13} \mathrm{CNMR}$ spectra, the results confirm the structure of AND.

\subsection{Technique of Weight Loss}

\subsubsection{Concentration Effect}

The inhibition efficiency (IE) esteems computed from weight reduction estimations for MS in the corrosive mixture that contain different concentrations of AND at encompassing temperature are appeared in
Fig.(5), that the AND diminished the corrosion of MS in corrosive media especially. The IE\% expanded with a rise in concentration of AND [15] and reached maximum IE at $50 \times 10^{-2} \mathrm{mM}$ concentration of AND. The raising in IE\% with raise in concentrations were prompsed of the raise in the extent of performance of AND protection. The inhibition efficiency of inhibitor for the corrosion of steel was obtained by using the following equation:

$$
I E(\%)=1-\frac{W \text { corr }}{W^{\circ} \text { corr }}
$$

Wcorr and $\mathrm{W}^{\circ}$ corr are the corrosion rate of steel samples with and without the inhibitor, respectively.

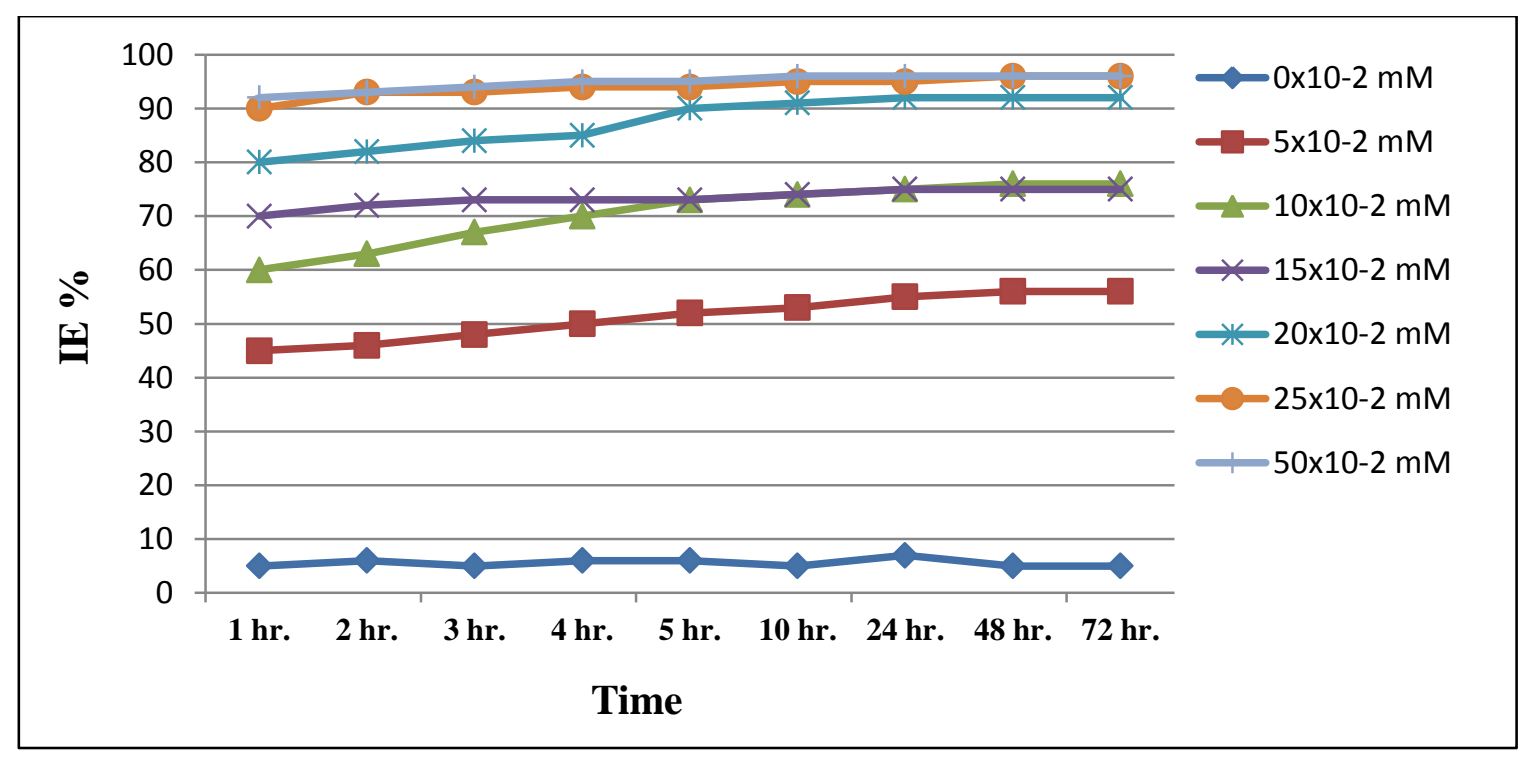

Fig.(5): Different concentrations of AND vis different immersion periods time for Inhibition Efficiency (IE \%) of mild steel.

\subsection{Scanning Electron Microscopy (SEM) Analysis}

SEM instrument examine is done at the UKM Electron Microscopy Unit. SEM analysis was performed to investigate the surface morphology of the mild steel after immersion in $1.0 \mathrm{M} \mathrm{HCl}$ in the absence and the presence of AND, Fig.(6) Damaged surface was observed in the absence of AND due to high dissolution rate of iron at such $\mathrm{pH}$ however a thin and uniform layer on the metal surface is observed in the presence of AND, the cracks in the film is due to the dehydration of surface since the surface was dried prior the SEM imaging. This is evidence that AND can be absorbed on the mild steel surface and insulates the surface from the acidic medium [16]. 


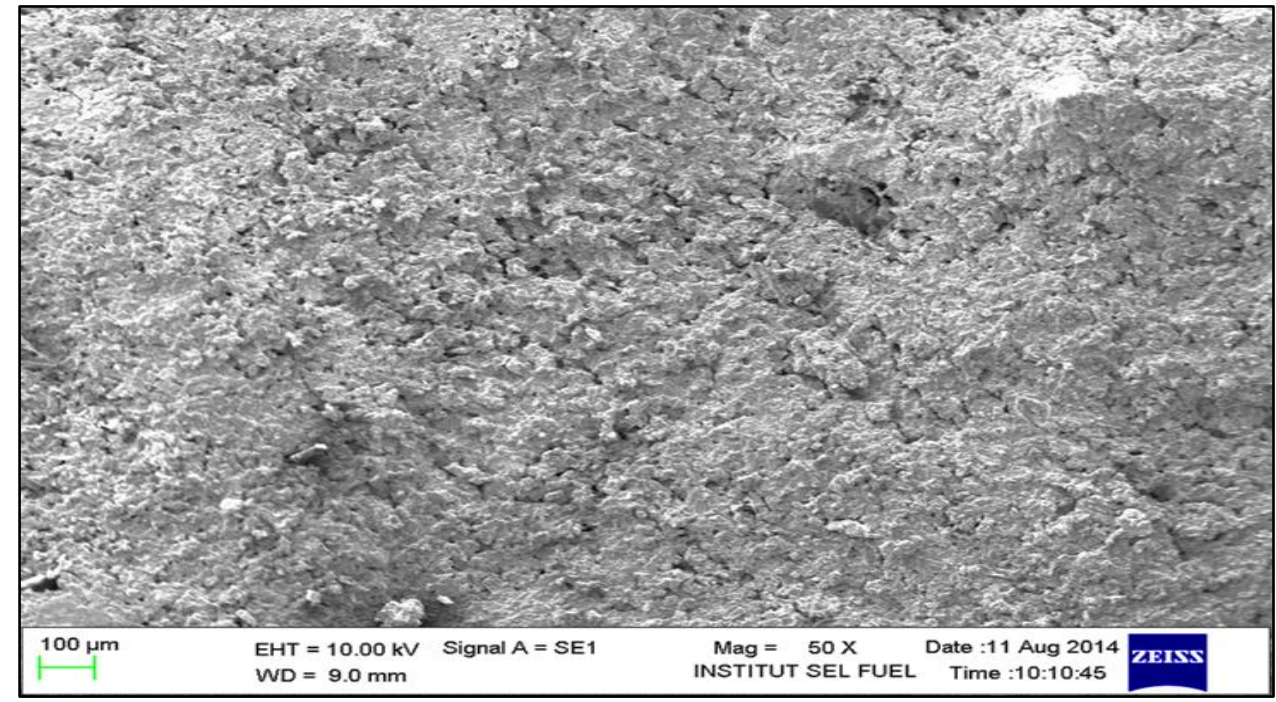

Fig.(6): The SEM pictures 5000X, of MS in solution of $\mathrm{HCl}$.

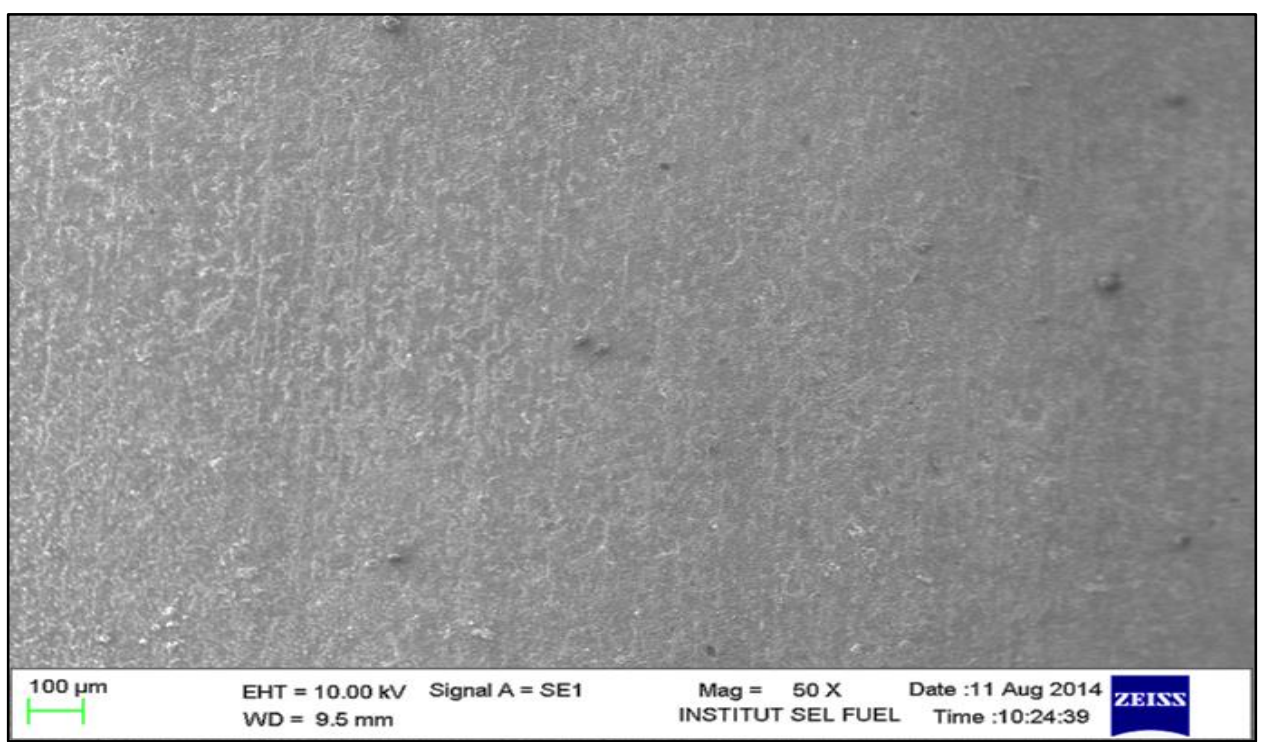

Fig.(7): SEM picture 5000X, for MS in solution of HCl with AND.

\section{Conclusions}

Results of this investigations revealed that the prepared coumarin derivative namely AND worked as an excellent corrosion inhibitor in corrosive media for surface MS in solution of $\mathrm{HCl}$ with concentration subordinate mode. Inhibition performance of AND as an inhibitor most extreme hindrance proficiency was up to $96 \%$ at $0.5 \mathrm{mM}$ AND concentration. AND is shows as a productive natural inhibitor having great inhibitive characteristics because of quality of atoms namely nitrogen with oxygen. SEM estimations bolstered development of a defensive layers through AND on the MS surface. The anti-corrosion investigation for AND showed the protection of surface of MS in corrosive solution.

\section{References}

[1] Ekpe U., "Inhibitory action of methyl and phenyl thiosemicarbazone derivatives on the corrosion of mild steel in hydrochloric acid". Materials chemistry and physics 40(2): 87-93, 1995.

[2] Quraishi M. and F. Ansari. "Corrosion inhibition by fatty acid triazoles for mild steel in formic acid". Journal of applied electrochemistry 33(3): 233-238, 2003.

[3] Quraishi M. and F. A. Ansari. "Fatty acid oxadiazoles as corrosion inhibitors for mild steel in formic acid". Journal of applied electrochemistry 36(3): 309-314, 2006.

[4] Onen A., "Corrosion inhibition potential and adsorption behaviour of bromophenol blue and thymol blue dyes on mild steel in acidic medium". International Journal of 
Electrochemical Science 6(7): 2884-2897, 2011.

[5] Wang L. "Inhibiting effect of 2mercaptopyrimidine on the corrosion of a low carbon steel in phosphoric acid". Corrosion science 43(9): 1637-1644, 2001.

[6] Khaled K. and N. Hackerman, "Investigation of the inhibitive effect of ortho-substituted anilines on corrosion of iron in $1 \mathrm{M} \mathrm{HCl}$ solutions". Electrochimica Acta 48(19): 2715-2723, 2003.

[7] Zhao J. and G. Chen., "The synergistic inhibition effect of oleic-based imidazoline and sodium benzoate on mild steel corrosion in a $\mathrm{CO}$ 2-saturated brine solution". Electrochimica Acta 69: 247-255, 2012.

[8] Shokry H., Yuasa, M Sekine, IIssa, RMElBaradie, HYGomma, GK. "Corrosion inhibition of mild steel by Schiff base compounds in various aqueous solutions" part 1. Corrosion science 40(12): 21732186, 1998.

[9] Majjane A., Rair, D Chahine, A Et-tabirou, M Touhami, M Ebn Touir, " Preparation and characterization of a new glass system inhibitor for mild steel corrosion in hydrochloric solution". Corrosion science 60: 98-103, 2012.

[10] Gopal D., Priyanka S., Shanthi P., "Inhibitive effect of chlorophytum borivilianum root extract on mild steel corrosion in $\mathrm{HCl}$ and $\mathrm{H}_{2} \mathrm{SO}_{4}$ solutions".Industrial \& Engineering Chemistry Research 52(31): 10673-10681, 2013.

[11] Al-Amiery A., Al-Majedy Y., Abdul Amir H., Abu Bakar. "New coumarin derivative as an eco-friendly inhibitor of corrosion of mild steel in acid medium". Molecules 20(1): 366-383, 2014.

[12] Loganayagi C., Kamal, C Sethuraman, MG, Opuntiol., "An active principle of opuntia elatior as an eco-friendly inhibitor of corrosion of mild steel in acid medium". ACS Sustainable Chemistry \& Engineering 2(4): 606-613, 2014.

[13] Khurana J. M., Jitender M Kumar, Sanjay, " DBU a highly efficient catalyst for one-pot synthesis of substituted 3, 4dihydropyrano [3,2-c] chromenes, dihydropyrano [4, 3-b] pyranes, 2-amino-
4H-benzo [h] chromenes and 2-amino-4H benzo [g] chromenes in aqueous medium". Tetrahedron 66(30): 5637-5641, 2010.

[14] Salami L., OP Akinyemi, RJ Patinvoh., "A study of the corrosion inhibitor of mild steel in sulphuric acid using Musa sapientum peels extract". Global Engineers and Technologists Review 2(12): 1-6, 2012.

[15] Tao Z., He, S Wang, S Zhang, G Zhou, "A study of differential polarization curves and thermodynamic properties for mild steel in acidic solution with nitrophenyltriazole derivative". Corrosion science 60: 205-213, 2012.

[16] Sokolova V., Anna-Kristin, "Characterisation of exosomes derived from human cells by nanoparticle tracking analysis and scanning electron microscopy". Colloids and Surfaces B: Biointerfaces 87(1): 146-150, 2011. 